\title{
Treatment and Prophylaxis of Post-pericardiotomy Syndrome in Cardiac Surgery Patients: a Systematic Review
}

\author{
Omar Giacinto ${ }^{1}$ - Alessandro Minati ${ }^{2} \cdot$ Mario Lusini $^{1} \cdot$ Francesco Cardetta $^{1} \cdot$ Sara Saltarocchi $^{2}$ (D) Mizar D'Abramo $^{2}$. \\ Fabio Miraldi ${ }^{2} \cdot$ Massimo Chello $^{1}$
}

Accepted: 6 September 2021

(c) The Author(s) 2021

\begin{abstract}
Purpose Post-pericardiotomy syndrome (PPS) is a common complication of cardiac surgery. This systematic review aimed to investigate the efficacy of colchicine, indomethacin, and dexamethasone in the treatment and prophylaxis of PPS.

Methods Literature research was carried out using PubMed. Studies investigating $\geq 10$ patients with clinically PPS treated with colchicine, dexamethasone, and indomethacin and compared with placebo were included. Animal or in vitro experiments, studies on $<10$ patients, case reports, congress reports, and review articles were excluded. Cochrane risk-of-bias tool for randomized trials (RoB2) was used for the quality assessment of studies.

Results Seven studies were included. Among studies with postoperative colchicine treatment, two of them demonstrated a significant reduction of PPS. In the single pre-surgery colchicine administration study, a decrease of PPS cases was registered. Indomethacin pre-surgery administration was linked to a reduction of PPS. No significant result emerged with preoperative dexamethasone intake.

Conclusion Better outcomes have been registered when colchicine and indomethacin were administered as primary prophylactic agents in preventing PPS and PE. Further RCT studies are needed to confirm these results.
\end{abstract}

Keywords Post-pericardiotomy syndrome $\cdot$ Colchicine $\cdot$ Indomethacin $\cdot$ Dexamethasone

\section{Introduction}

Post-pericardiotomy syndrome (PPS) is a common complication of cardiac surgery that affects the pericardium and pleurae and is associated with significant morbidity and prolonged in-hospital stay. Although PPS pathophysiology remains unclear [1], surgical trauma and cardiopulmonary bypass (CPB) are reported as essential factors in triggering a systemic inflammatory response syndrome (SIRS) [2].

A single dose of long-acting corticosteroids is usually given during heart surgery to attenuate the inflammatory response, but definitive results of its efficacy are lacking [3].

Sara Saltarocchi

sara.saltarocchi@uniroma1.it

1 Department of Cardiovascular Surgery, University Campus Bio-Medico, Rome, Italy

2 Department of Clinical, Internal Medicine, Anesthesiology and Cardiovascular Sciences, Sapienza University of Rome, Rome, Italy
Few days after surgery until the follow-up period, the pleuro-pericardial effusion may be detected, often complicating the postoperative course. In most cases, the accumulated fluid may cause respiratory distress (atelectasis) and infections, leading to a prolonged hospital stay or intensive care unit (ICU) admission [4]. Diagnosis of pericardial effusion relies on postoperative echocardiography, while pleural effusion (PE) is usually diagnosed through chest $\mathrm{x}$-ray.

Although nonsteroidal anti-inflammatory drugs (NSAIDs), steroids, and colchicine are indicated as effective pharmacological agents to treat these conditions, side effects and secondary withdrawal of the medicaments could reduce their effectiveness [4-6]. To date, there is no scientific evidence of the resolution or prevention of PPS with a specific drug.

This systematic review aimed to investigate the role of current treatments in preventing or reducing cardiac surgery complications due to PPS or PE. 


\section{Methods}

The materials and methods were based on the PRISMA (Preferred Reporting Items for Systematic Reviews and Meta-Analysis) guidelines [7]. A systematic search was carried out on PubMed from September 2020 to April 2021 without time and language restrictions.

The components of the PICOS question were as follows: (patients) patients undergoing heart surgery; (intervention) colchicine, dexamethasone, or indomethacin; (comparison) placebo; (outcome) onset of PPS or PE; (study design) RCT.

The literature search strategy was based on the following keywords: (pericarditis OR pericardial effusion OR pleuro-pericardial syndrome) AND (colchicine OR dexamethasone OR indomethacin) AND (heart surgery).

\section{Study Selection and Selection Criteria}

Studies on $\geq 10$ patients with clinical pericarditis or postpericardiotomy syndrome in which colchicine, dexamethasone, and indomethacin were compared with placebo were included. Publications referring only to animal or in vitro experiments, human studies on $<10$ patients, case reports, congress reports, and review articles were excluded.

The complete list of articles obtained through the systematic search was scrutinized to remove duplicates and select the potentially relevant articles based on the title to answer the research question. Subsequently, the abstract screening was performed as well. The eligible studies were independently selected by two reviewers (OG and AM). From the remaining potentially relevant articles, those that met the inclusion and exclusion criteria were selected through full-text reading. Articles that did not meet inclusion criteria were not included in the present study.

The subsequent article selection was independently done by two authors (OG and AM). When there was disagreement, a third experienced reviewer was consulted to achieve a consensus.

The primary endpoint of the study was to investigate the efficacy of colchicine, dexamethasone, and indomethacin in the treatment and prevention of PPS and pleural effusion. The secondary endpoints were to assess the effectiveness of the three drugs in reducing hospital readmission, cardiac tamponade, symptom persistence, and atrial fibrillation after $72 \mathrm{~h}$, as well as the safety and adverse effects of pharmacological treatment.

\section{Data Extraction}

Two reviewers ( $\mathrm{OG}$ and $\mathrm{AM}$ ) independently extracted the data from the full texts of the studies that fulfilled the inclusion criteria. Disagreements were resolved through team discussions.

Data extraction was organized in tables that included the following information:

1. Study characteristics: first author, year, intervention arms, number of patients, randomization, and blinding

2. Patients' clinical characteristics

3. Treatment indication and duration

4. Pharmacological dosage

5. Follow-up

6. Clinical outcomes

\section{Data Synthesis}

All the data from the eligible articles were synthesized into a systematic summary. The characteristics of each study were reported. It was planned to synthesize a quantitative analysis (meta-analysis), but the methodology was not homogeneous among the included studies, and few studies were selected for indomethacin and dexamethasone.

\section{Risk of Bias Assessment}

The quality of each RCT was independently assessed according to the Cochrane Risk of Bias Tool (RoB2) by two reviewers. Five domains of bias (i.e., randomization process, deviations from intended interventions, missing outcome data, measurement of the outcome, and selection of the reported results) were evaluated and reported. The Cochrane Handbook for Systematic Reviews of Interventions was used as a reference guide during the evaluation [8]. A judgment of "high" indicated a high risk of bias, "low" indicated a low risk of bias, and "some concerns" indicated the presence of bias due to lack of information or uncertainty about the potential for bias. Thus, the studies were categorized as having a low or high risk of bias or some concerns. Any discrepancy in the assessment of RoB2 was discussed to attain a consensus.

\section{Results}

\section{Study Selection and Quality Assessment}

In this review, we examined an amount of 361 studies from 1977 to 2019 . We included only seven randomized 
Fig. 1 PRISMA flowchart

\section{Identification of studies via databases and registers}

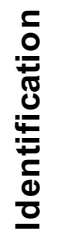

\author{
Records identified from*: \\ Databases $(n=361)$ \\ Registers $(n=0)$
}

Records screened

$(n=361)$

Records excluded**
$(n=343)$

Reports not retrieved

$(n=0)$

Reports sought for retrieval

๗

$(n=18)$

Reports assessed for eligibility

$(n=18)$

\author{
Records removed before \\ screening: \\ Duplicate records removed \\ $(n=0)$
}

$\begin{array}{ll}\text { 엉 } & \text { Studies included in review } \\ \frac{(n=7)}{2} & \text { Reports of included studies } \\ \text { 응 } & (n=7)\end{array}$

controlled trials [4, 9-14] (Fig. 1). Five trials investigated colchicine [4, 10-13], one indomethacin [9], and one dexamethasone [14]. Six were double-blind randomized trials [4, 9, 11-14], and one was a triple-blind randomized trial [10]. Five studies were multicenter trials [4, 11-14], while two studies were single-center randomized trials $[9,10]$. Follow-up period varied from 1 to 12 months. The weightadjusted colchicine dosage was $0.5 \mathrm{mg} / \mathrm{kg}$ in three studies $[4,11,13]$ and $1 \mathrm{mg}$ daily in two studies [10, 12].

The duration of colchicine treatment was between 14 and 30 days. It was started $48-72 \mathrm{~h}$ before surgery in one trial [11], on the $3^{\text {rd }}$ postoperative day in two trials $[4,13]$, on the $7^{\text {th }}$ day in another trial [10], and 30 days after heart surgery in one trial [12].

Indomethacin dosage was $25 \mathrm{mg} 3$ times/day for three days before surgery in one trial [9]. Treatment duration lasted for 6 weeks after the surgery.
Dexamethasone dosage was $1 \mathrm{mg} / \mathrm{Kg}$ i.v. as a single intraoperative bolus in one trial [14]. Studies characteristics are reported in Table 1.

Only five patients got lost during the follow-up of all studies. The groups did not differ in clinical characteristics and type of surgery. The seven prospective studies from 2002 to 2015 included 1,677 patients (mean age 60.8, male $67.4 \%$ ). Baseline characteristics of treatment and control groups in all studies are reported in Table 2.

Two studies were considered to have a "high" risk of bias [9, 13], two studies were considered to have "some concern" [10,14], and three studies were considered to have a "low" risk of bias $[11,12,15]$. The risk of bias of each randomized clinical trial is reported in Fig. 2. 


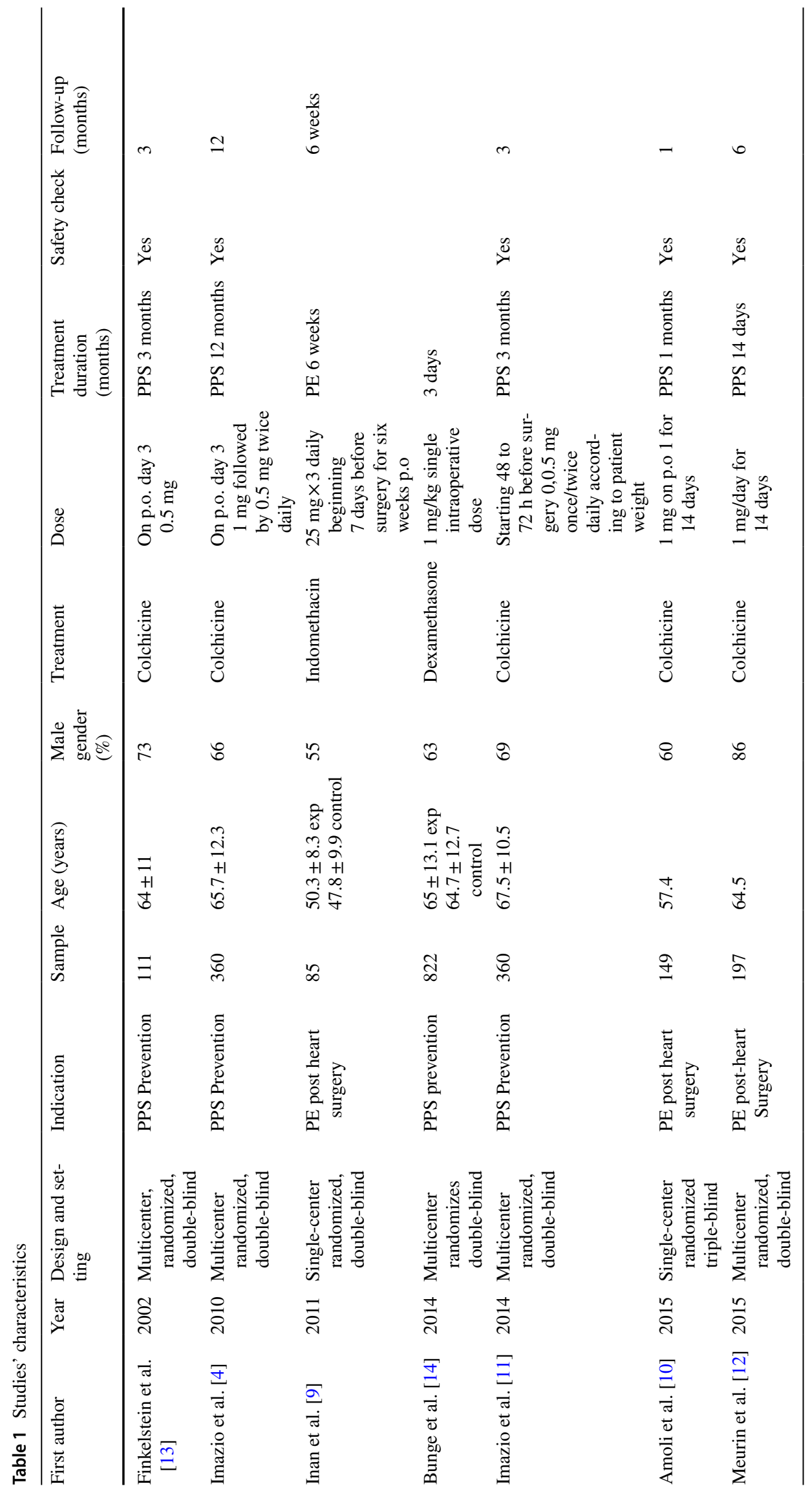




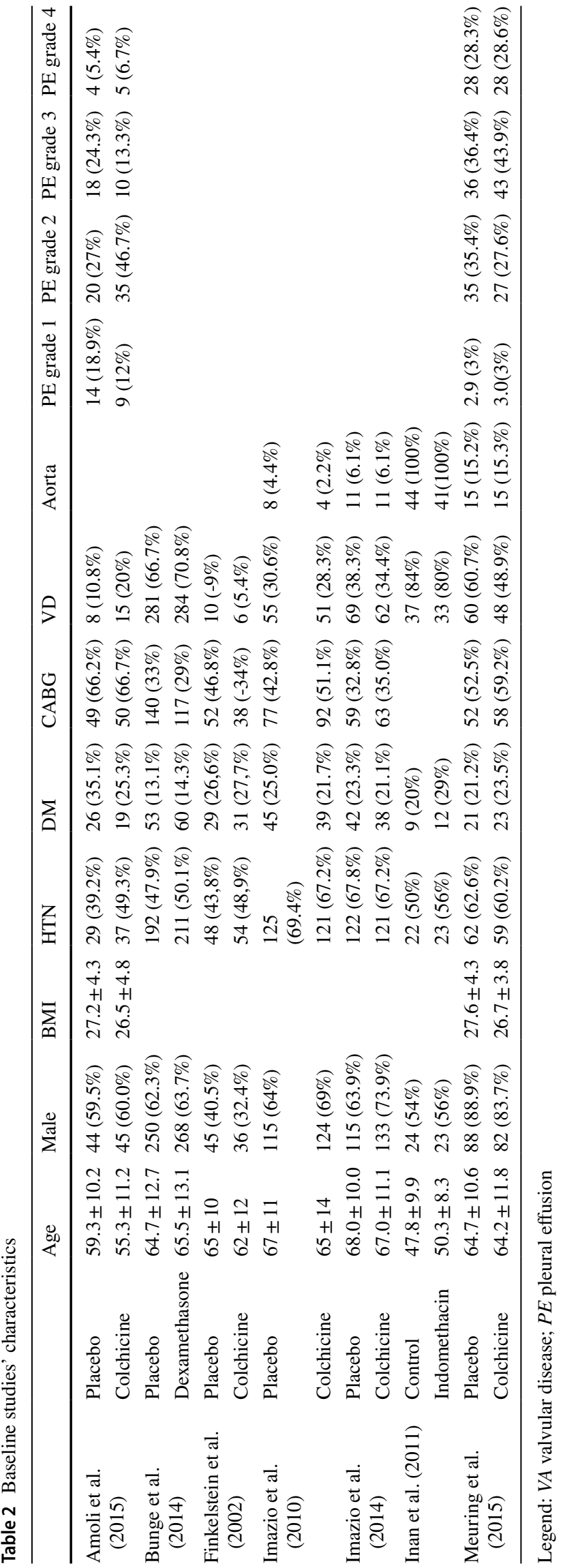

\section{Main Outcomes}

Primary endpoints were related to registering the reduction of pericardial and pleural effusion in all the studies examined, while there was no homogeneity with secondary endpoints in the study groups.

Adverse effects contemplated gastrointestinal intolerance (GI), allergic reactions (AR), renal failure (RF), pancreatitis (PR), hepatotoxicity (HT), alopecia (AP), and leucopenia (LP) [4, 9-13]. Adverse effects ranged from 7 to $20 \%$ [4, 9-13].

Finkelstein et al. (2002), Imazio et al. (2010, 2014) study (all three studies referred to colchicine) and Inan et al. (2011) (indomethacin) reported as results a reduction of PPS and PE. On the contrary, Meurin et al. (2015), Amoli et al. (2015), and Bunge et al.'s study (2014) (dexamethasone) registered no reduction of PPS or PE.

\section{Colchicine}

Finkelstein et al. (2002) demonstrated a better outcome for patients undergoing colchicine treatment. PPS was diagnosed in 19 patients $(17.1 \%), 5 / 47$ cases $(10.6 \%)$ in the colchicine group, and 14/64 (21.9\%) in the placebo group, although without statistically significant difference $(p=0.135)$ [13]. Imazio et al. (2010) reported a significant reduction of the incidence of the PPS at 12 months in the colchicine group $(p=0.002)$ and in the secondary endpoints (hospitalization, cardiac tamponade, constrictive pericarditis, and relapses) at 18 months $(p=0.024)$. The rates of side effects and drug withdrawal were similar in the colchicine and placebo groups, although the colchicine group showed a trend towards an increased rate of both events. No severe side effects were recorded [4]. The same trend was confirmed in Imazio et al. (2014), where a significant reduction of incidence of PPS was also reported. PPS emerged in 35 patients (19.4\%) assigned to colchicine group and 53 (29.4\%) assigned to placebo group (absolute difference, $10.0 \%$; 95\% CI, 1.1-18.7\%; number needed to treat $=10$ ). There were no significant differences between the colchicine and placebo groups for the secondary endpoints of postoperative AF (colchicine: 61 patients [33.9\%]; placebo: 75 patients [41.7\%]; absolute difference: $7.8 \%$; $95 \% \mathrm{CI},-2.2$ to $17.6 \%$ ) or postoperative pericardial/pleural effusion (colchicine: 103 patients [57.2\%]; placebo: 106 patients [58.9\%]; absolute difference: $1.7 \%$; $95 \% \mathrm{CI},-8.5$ to $11.7 \%$ ), although there was a reduction in postoperative $\mathrm{AF}$ in the prespecified on-treatment analysis (placebo: 61/148 patients [41.2\%]; colchicine: $38 / 141$ patients [27.0\%]; absolute difference: $14.2 \%$; 95\% CI, 3.3-24.7\%). Adverse effects, mainly gastrointestinal events, were more frequently detected in the colchicine group [11]. 


$\begin{array}{llllll}\text { Unique ID } & \text { Study ID } & \underline{\text { Year }} & \text { Experimental } & \text { Comparator } & \text { Outcome } \\ 1 & \text { Amoli et al. } & 2015 & \text { Colchicine } & \text { Placebo } & \text { PE } \\ 2 & \text { Bunge et al. } & 2014 & \text { Dexamethasone } & \text { Placebo } & \text { PPS } \\ 3 & \text { Finkelstein et al. } & 2002 & \text { Colchicine } & \text { Placebo } & \text { PPS } \\ 4 & \text { Imazio et al. } & 2010 & \text { Colchicine } & \text { Placebo } & \text { PPS } \\ 5 & \text { Imazio et al. } & 2014 & \text { Colchicine } & \text { Placebo } & \text { PPS } \\ 6 & \text { Inan et al. } & 2011 & \text { Indomethacin } & \text { Placebo } & \text { PE } \\ 7 & \text { Meurin et al. } & 2015 & \text { Colchicine } & \text { Placebo } & \text { PE }\end{array}$

Fig. 2 Risk of bias RoB2

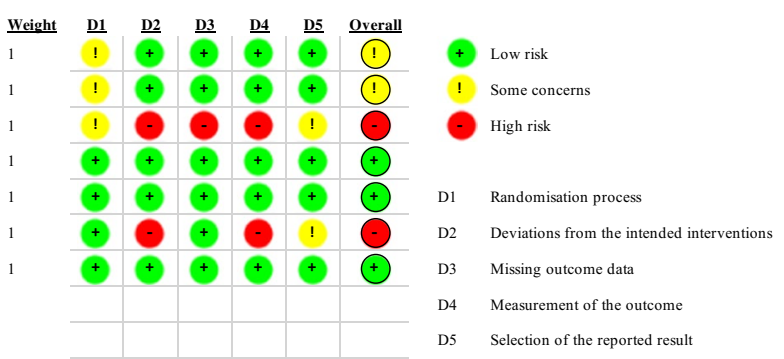

Different results in the comparisons between colchicine and placebo were registered in Meurin et al. (2015) and Amoli et al. (2014), who reported no statistically significant difference between the two groups in the incidence of PPS (Meurin et al. $p=0.23$; Amoli et al. $p=0.44$ ). Mainly, Meurin et al. (2015) observed a similar decrease in mean pericardial effusion from baseline after treatment $(-1.1 \pm 1.3$ vs. $-1.3 \pm 1.3$ grades) in the colchicine and control group, respectively, without statistically significant mean difference between groups $(-0.19 ; 95 \% \mathrm{CI}-0.55$ to $0.16, p=0.23)$. In addition, no differences between colchicine and control groups were registered in the secondary endpoints in both studies [10, 12].

\section{Indomethacin}

Inan et al. (2011) explored the indomethacin effect on pericardial effusion when administered seven days before surgery and continued for six weeks after the operation. During hospitalization and follow-up, one patient in the indomethacin group and eight in the control group had significant pericardial effusion $(p=0.019)$ [9].

\section{Dexamethasone}

Bunge et al. (2014), who compared $1 \mathrm{mg} / \mathrm{kg}$ single dose intraoperative dexamethasone with the placebo group, reported no statistically significant difference between groups for primary prophylaxis on PPS. The incidence of PPS after drugs intake compared with placebo was $13.5 \%$ and $15.5 \%$ (relative risk $0.88,95 \%$ CI $0.63-1.22$ ). Complicated PPS had an incidence of $3.8 \%$ and $3.2 \%$, respectively (relative risk $1.17,95 \%$ CI $0.57-2$ ). Also, for secondary endpoints, there was no statistical significance [14].

Complete results of primary and secondary endpoints are reported in Table 3.

\section{Discussion}

PPS presents with pleural or pericardial reaction, with symptomatology depending on the inflammatory response triggered after surgery. CBP time, surgical trauma, duration of the operation, and associated cytokine levels are thought to be essential factors in triggering a SIRS that leads to PPS [16-19].

The best management of pleural effusion is controversial. Clear indications on the right timing to perform a thoracentesis are lacking. Usually, a pleural effusion is complicated when thoracentesis is needed and is accompanied by alterations in clinical and arterial blood gas (ABG) parameters. Nonsteroidal anti-inflammatory drugs, colchicine, and steroids can be employed. Thoracentesis is typically performed as a final resort, considering that this procedure is not free from complications such as hemorrhage and pneumothorax. Pericardiocentesis is performed when the increased pressure in the pericardial cavity leads to echocardiographic signs of cardiac chambers compression (right and left atrial collapse, ventricular collapse, swinging heart, etc.) and subsequent hemodynamic instability.

In this systematic review, we identified seven randomized trials about the effectiveness of colchicine (5 studies), indomethacin (1 study), and dexamethasone (1 study) when used for primary prophylaxis purposes. The included studies had enrolled many patients, except for the indomethacin study [9], which was executed using a small sample. Finkelstein et al. (2002) performed a prospective, randomized, double-blind study. They demonstrated the statistical significance of the colchicine treatment in reducing PPS. No significant data were reported on specific secondary endpoints and adverse effects [13]. Imazio et al. (2010) demonstrated the efficacy of colchicine in reducing PPS events relating this reduction to pharmacological effects of colchicine on cells involved in the inflammation process. Colchicine may inhibit various leukocyte functions and has a preferential concentration in leukocytes [4]. 
Table 3 Primary and secondary endpoints

\begin{tabular}{|c|c|c|c|c|c|c|}
\hline \multirow[t]{2}{*}{ Authors } & \multicolumn{3}{|l|}{ Primary endpoints } & \multicolumn{3}{|l|}{ Secondary endpoints } \\
\hline & & Placebo & Treatment & & Placebo & Treatment \\
\hline \multirow[t]{3}{*}{ Amoli et al. (2015) } & Pretreatment PE variation & $10.8 \pm 2.5 \mathrm{~mm}$ & $10.4 \pm 2.4$ & $\begin{array}{l}\text { Echocardiographic PE } \\
\text { follow-up } \\
\text { Mild }\end{array}$ & $48 \%$ & $28.6 \%$ \\
\hline & $\begin{array}{l}\text { Post-treatment } \\
\text { PE variation }\end{array}$ & $6.7 \pm 6 \mathrm{~mm}$ & $6.92 \pm 5.5 \mathrm{~mm}$ & $\begin{array}{l}\text { Echocardiographic PE } \\
\text { follow-up } \\
\text { Moderate }\end{array}$ & & $24.5 \%$ \\
\hline & & & & $\begin{array}{l}\text { Echocardiographic PE } \\
\text { follow-up } \\
\text { Minimal }\end{array}$ & & $24.5 \%$ \\
\hline \multirow[t]{4}{*}{ Bunge et al. (2014)* } & PPS & $62(15.5 \%)$ & $57(13.5 \%)$ & Complicated PPS & $13(3.2 \%)$ & $16(3.8 \%)$ \\
\hline & Fever & $64(16 \%)$ & $56(13.3 \%)$ & $\begin{array}{l}\text { Pericardiocentesis/thora- } \\
\text { cotomy for tamponade }\end{array}$ & $8(2 \%)$ & $11(2.6 \%)$ \\
\hline & Pericardial rubbing & $87(21.7 \%)$ & $102(24.2 \%)$ & Evacuation for PE & $4(1 \%)$ & $5(1.2 \%)$ \\
\hline & & & & Readmission for PPS & $8(2 \%)$ & $3(0.7 \%)$ \\
\hline Finkelstein et al. (2002) & PPS & $14(21.9 \%)$ & $5(10.6 \%)$ & Pericarditis & $17(27 \%)$ & $6(12 \%)$ \\
\hline \multirow[t]{6}{*}{ Imazio et al. (2010) } & PPS at 12 months & $38(21.1 \%)$ & $16(8.9 \%)$ & Recurrence & $2(1.1 \%)$ & 0 \\
\hline & Fever 1 po week & $7(3.9 \%)$ & $6(3.3)$ & Cardiac tamponade & $1(0.6 \%)$ & 0 \\
\hline & Pleuritic chest pain & $23(12.8 \%)$ & $7(3.9 \%)$ & Constrictive pericarditis & 0 & 0 \\
\hline & Friction rub & $15(8.3 \%)$ & $5(2.7 \%)$ & PPS-related hospitalization & $6(3.3 \%)$ & $1(0.6 \%)$ \\
\hline & Pleural effusion & $46(25.6 \%)$ & $22(12.2 \%)$ & & & \\
\hline & $\begin{array}{l}\text { New or worsening pericar- } \\
\text { dial effusion }\end{array}$ & $41(22.8 \%)$ & $23(12.8 \%)$ & & & \\
\hline \multirow[t]{8}{*}{ Imazio et al. (2014) } & PPS within 3 months & $53(29.4 \%)$ & $35(19.4 \%)$ & $\mathrm{PO} \mathrm{AF}$ & $75(41.7 \%)$ & $61(33.9 \%)$ \\
\hline & & & & $\begin{array}{l}\text { PO pericardial /pleural } \\
\text { effusion }\end{array}$ & $106(58.9 \%)$ & $103(57.2 \%)$ \\
\hline & & & & Cardiac tamponade & $3(1.7 \%)$ & $1(0.6 \%)$ \\
\hline & & & & $\begin{array}{l}\text { Pericardiocentesis /thora- } \\
\text { centesis }\end{array}$ & $13(7.2 \%)$ & $13(7.2 \%)$ \\
\hline & & & & PPS recurrence & $3(1.7 \%)$ & $3(1.7 \%)$ \\
\hline & & & & $\begin{array}{l}\text { Disease-related readmis- } \\
\text { sion }\end{array}$ & $2(1.1 \%)$ & $2(1.1 \%)$ \\
\hline & & & & Overall mortality & $2(1.1 \%)$ & $6(3.3 \%)$ \\
\hline & & & & Stroke & $1(0.6 \%)$ & $2(1.1 \%)$ \\
\hline Inan et al. (2011)** & Plural effusion ( $0-14$ days) & $5(11.3 \%)$ & 0 & $\begin{array}{l}\text { Pleural effusion } \\
\text { (2-6 weeks) }\end{array}$ & $3(6.8 \%)$ & $1(2.4 \%)$ \\
\hline \multirow[t]{4}{*}{ Meurin et al. (2015 } & Pericardial effusion & $1.1 \pm 1.3 \mathrm{~cm}$ & $1.3 \pm 1.3 \mathrm{~cm}$ & Tamponade & $7(7 \%)$ & $6(6 \%)$ \\
\hline & & & & $\begin{array}{l}\text { Mean effusion width } \\
\text { change from baseline }\end{array}$ & $4.7 \pm 6.9 \mathrm{~mm}$ & $5.8 \pm 6.6 \mathrm{~mm}$ \\
\hline & & & & $\begin{array}{l}\text { Echocardiographic grade } \\
\text { decrease }\end{array}$ & $66.7 \%$ & $74.5 \%$ \\
\hline & & & & $\mathrm{AF}$ & $12.1 \%$ & $15.3 \%$ \\
\hline
\end{tabular}

*Dexamethasone

**indomethacin

Imazio et al. (2014) showed that preoperative administration of colchicine significantly reduced postoperative inflammation and its complication, especially PPS. As suggested by subgroup analysis, colchicine was more efficacious against $\mathrm{C}$-reactive protein elevation. They avoided a loading dose and used weight-adjusted doses to obtain a higher degree of treatment adherence. However, high rates of adverse events were registered, such as gastrointestinal intolerance and drug discontinuation. These findings suggested that colchicine must be employed only in wellselected patients [11]. 
Meurin et al. (2015), assessing the effectiveness of colchicine to treat asymptomatic postoperative pericardial effusion, observed that the use of the colchicine did not significantly reduce the volume of PE [12]. The authors justified the absence of efficacy considering the inflammatory etiology not being the main trigger of PE, considering more likely aetiologies postoperative hemorrhagic effusion and PE secondary to heart failure. Nevertheless, they concluded that in patients with PPS, colchicine might be efficacious, as described in the ICAP study [15].

Izadi Amoli et al. (2015) performed a 2-week triple-blind trial comparing the effectiveness of colchicine in a high turnover specialized setting. The authors found no difference in the two groups regarding postoperative mild to moderate PE [10].

Two meta-analyses seem to agree with our findings of the efficacy of colchicine [20, 21].

Inan et al. (2011) investigated the prophylactic indomethacin effect on postoperative PE. Within the limitations of the low number of enrolled patients, the results of this study suggest that preoperative indomethacin intake may have a beneficial role on the outcome and incidence of postoperative PE. The authors' conclusions indicated indomethacin as an alternative to other drugs to avoid postoperative PE [9].

Bunge et al. (2014) found no protective effect of a single high intraoperative dose of dexamethasone on PPS or complicated PPS in a cohort of patients undergoing valvular surgery [14].

\section{Conclusion}

PPS and PE are the epiphenomena of the inflammatory status secondary to heart surgery, especially when CPB is adopted. Therefore, PPS and PE treatments on cardiac surgery are central concerns in avoiding complications such as cardiac tamponade or infections in the first postoperative days.

Limitations of the study were to be found in the heterogeneity of the population and the timing of drug administration. In the studies with postoperative colchicine administration, 2 of them demonstrated a significant reduction of PE. In the single pre-surgery colchicine administration study, a reduction of PE was obtained as well. In the indomethacin study, pre-surgery administration was linked to a reduction of PE. This result was not reported with pre-operatively dexamethasone intake. The included studies also demonstrated no reduction in PE of non-inflammatory etiology. In future studies, it could be helpful that this feature is excluded from primary endpoints.

Our findings showed a better outcome when colchicine and indomethacin were administered as primary prophylactic agents in reducing the risk of PPS and PE. Given their low adverse effects rates, clinical administration of colchicine and indomethacin in the preoperative setting could be considered an optimal solution to prevent PPS and PE.

Author contributions All authors contributed significantly to this work and approved its final version.

Funding Open access funding provided by Università degli Studi di Roma La Sapienza within the CRUI-CARE Agreement.

Availability of Data and Material Available from the corresponding author upon request.

Code Availability Not applicable.

\section{Declarations}

Ethics Approval Not applicable.

Consent to Participate Not applicable.

Consent for Publication Not applicable.

Conflict of Interest The authors declare no competing interests.

Open Access This article is licensed under a Creative Commons Attribution 4.0 International License, which permits use, sharing, adaptation, distribution and reproduction in any medium or format, as long as you give appropriate credit to the original author(s) and the source, provide a link to the Creative Commons licence, and indicate if changes were made. The images or other third party material in this article are included in the article's Creative Commons licence, unless indicated otherwise in a credit line to the material. If material is not included in the article's Creative Commons licence and your intended use is not permitted by statutory regulation or exceeds the permitted use, you will need to obtain permission directly from the copyright holder. To view a copy of this licence, visit http://creativecommons.org/licenses/by/4.0/.

\section{References}

1. Mack DR, Cahoon WD, Lowe DK. Colchicine for the primary prevention of the postpericardiotomy syndrome. Ann Pharmacother. 2011;45:803-6. http://journals.sagepub.com/doi/10.1345/ aph.1Q112.

2. Wan S, LeClerc J-L, Vincent J-L. Inflammatory Response to Cardiopulmonary Bypass. Chest. 1997;112:676-92. https://linki nghub.elsevier.com/retrieve/pii/S0012369216317354.

3. Dieleman JM, van Paassen J, van Dijk D, Arbous MS, Kalkman CJ, Vandenbroucke JP, et al. Prophylactic corticosteroids for cardiopulmonary bypass in adults. Cochrane Database Syst Rev. 2011. https://onlinelibrary.wiley.com/doi/10.1002/14651858. CD005566.pub3.

4. Imazio M, Trinchero R, Brucato A, Rovere ME, Gandino A, Cemin R, et al. Colchicine for the Prevention of the Post-pericardiotomy Syndrome (COPPS): a multicentre, randomized, doubleblind, placebo-controlled trial. Eur Heart J. 2010;31:2749-54. https://academic.oup.com/eurheartj/articlelookup/doi/10.1093/ eurheartj/ehq319. 
5. Jadad AR, Carroll D, Moore A, McQuay H. Developing a database of published reports of randomised clinical trials in pain research 1. Pain. 1996;66:239-46. http://journals.lww.com/00006 396-199608000-00017.

6. Dieleman JM, de Wit GA, Nierich AP, Rosseel PM, van der Maaten JM, Hofland J, et al. Long-term outcomes and cost effectiveness of high-dose dexamethasone for cardiac surgery: a randomised trial. Anaesthesia. 2017;72:704-13. https://onlinelibrary. wiley.com/doi/10.1111/anae.13853.

7. Moher D, Liberati A, Tetzlaff J, Altman DG. Preferred reporting items for systematic reviews and meta-analyses: the PRISMA statement. PLoS Med. 2009;6:e1000097. https://dx.plos.org/10. 1371/journal.pmed.1000097.

8. Higgins JPT, Altman DG, Gøtzsche PC, Jüni P, Moher D, Oxman AD, et al. The Cochrane Collaboration's tool for assessing risk of bias in randomised trials. BMJ (Clinical research ed). 2011;343:d5928.

9. Inan MB, Yazıcıoglu L, Eryılmaz S, Sırlak M, Cetıntas D, Kaya B, et al. Effects of prophylactic indomethacin treatment on postoperative pericardial effusion after aortic surgery. J Thorac Cardiovasc Surg. 2011;141:578-82. https://linkinghub.elsevier.com/retrieve/ pii/S0022522310003168.

10. Izadi Amoli A, Bozorgi A, HajHossein Talasaz A, Salehi Omran A, Mortazavi SH, Jalali A, et al. Efficacy of colchicine versus placebo for the treatment of pericardial effusion after open-heart surgery: a randomized, placebo-controlled trial. Am Heart J. 2015;170:1195-201. https://linkinghub.elsevier.com/retrieve/pii/ S0002870315006079.

11. Imazio M, Brucato A, Ferrazzi P, Pullara A, Adler Y, Barosi A, et al. Colchicine for prevention of postpericardiotomy syndrome and postoperative atrial fibrillation. JAMA. 2014;312:1016. http:// jama.jamanetwork.com/article.aspx?doi=10.1001/jama.2014. 11026.

12. Meurin P, Lelay-Kubas S, Pierre B, Pereira H, Pavy B, Iliou MC, et al. Colchicine for post-operative pericardial effusion. J Am Coll Cardiol. 2015;66:1198-9. https://linkinghub.elsevier.com/retrieve/ pii/S0735109715043041.

13. Finkelstein Y, Shemesh J, Mahlab K, Abramov D, Bar-El Y, Sagie A, et al. Colchicine for the prevention of postpericardiotomy syndrome. Herz. 2002;27:791-4. http://link.springer.com/10.1007/ s00059-002-2376-5.
14. Bunge JJH, van Osch D, Dieleman JM, Jacob KA, Kluin J, van Dijk D, et al. Dexamethasone for the prevention of postpericardiotomy syndrome: a DExamethasone for Cardiac Surgery substudy. Am Heart J. 2014;168:126-131.e1. https://linkinghub.elsevier. com/retrieve/pii/S000287031400163X.

15. Imazio M, Brucato A, Cemin R, Ferrua S, Maggiolini S, Beqaraj $\mathrm{F}$, et al. A randomized trial of colchicine for acute pericarditis. $\mathrm{N}$ Engl J Med. 2013;369:1522-8. http://www.nejm.org/doi/10.1056/ NEJMoa1208536.

16. van Osch D, Nathoe HM, Jacob KA, Doevendans PA, van Dijk $\mathrm{D}$, Suyker WJ, et al. Determinants of the postpericardiotomy syndrome: a systematic review. Eur J Clin Invest. 2017;47:456-67. https://onlinelibrary.wiley.com/doi/10.1111/eci.12764.

17. Erlich JF, Paz Z. Postpericardial injury syndrome: an autoimmune phenomenon. Clin Rev Allergy Immunol. 2010;38:156-8. http:// link.springer.com/10.1007/s12016-009-8147-9.

18. Kim S, Sahn SA. Postcardiac Injury Syndrome. Chest. 1996;109:570-2. https://linkinghub.elsevier.com/retrieve/pii/ S001236921545696X.

19. Jaworska-Wilczyńska M, Magalska A, Piwocka K, Szymański P, Kuśmierczyk M, Wąsik M, et al. Low interleukin - 8 level predicts the occurrence of the postpericardiotomy syndrome. Pizzi C, editor. PLoS ONE. 2014;9:e108822. https://dx.plos.org/10.1371/ journal.pone.0108822.

20. Agarwal SK, Vallurupalli S, Uretsky BF, Hakeem A. Effectiveness of colchicine for the prevention of recurrent pericarditis and post-pericardiotomy syndrome: an updated meta-analysis of randomized clinical data. Eur Heart J Cardiovasc Pharmacother. 2015;1:117-25. https://academic.oup.com/ehjcvp/article-lookup/ doi/10.1093/ehjcvp/pvv001.

21. Lutschinger LL, Rigopoulos AG, Schlattmann P, Matiakis M, Sedding D, Schulze PC, et al. Meta-analysis for the value of colchicine for the therapy of pericarditis and of postpericardiotomy syndrome. BMC Cardiovasc Disord. 2019;19:207. https:// bmccardiovascdisord.biomedcentral.com/articles/10.1186/ s12872-019-1190-4.

Publisher's Note Springer Nature remains neutral with regard to jurisdictional claims in published maps and institutional affiliations. 